\title{
The Hegemony of Western Categorisation and the Underdevelopmentof Children's Literature in 'Other' Worlds
}

\author{
Ming Cherng Duh
}

This paper seeks to explore some problems relating to academic research in children's literature as faced by graduate students and scholars in Taiwan, to discuss the extent to which the development of children's literature in other countries may be dependent on Western modes of though, to explain some of the causes of this phenomenon, and to suggest a few approaches for a healthier and more balanced development in global children's literature studies. I apply perspectives (and metaphors) from the field of sociology of development to argue that scholarship is dominated by Western nations, whose cultural products represent hegemony. On the other hand, smaller, peripheral nations cannot but become less and less autonomous in their cultural production. In this capitalist world system, the satellite nations are assimilated into metropolitan centres under the ideology of common good and sometimes in the guise of cultural pluralism.

Sociology of development focuses mainly on theories relating to political economies. As early as the mid twentieth century, scholars in the West tried to explain and prescribe means to modernise less developed countries. These theories of modernisation which promoted ways of following Western experience for economic achievement and political democracy were challenged in the 1970s by theorists from South America, Asia and Africa who developed the field of dependency theory, largely inspired by Marx's theory of alienation and Lenin's theory of imperialism. According to dependency theory, the process of external expansion of industrialised nations both assisted the economic development of Western countries and impoverished much of the rest of the world. Once the notion of wealth distribution was determined, Western countries have been able to perpetuate their privileged position as long as they control the terms of world trade. For dependency theorists, global society has developed in an uneven way, in that the core nations (United States, Europe and Japan) occupy a dominant role with the dominated countries being dependent on them (Cardoso 1972). Andre Frank (1969) coined the term 'development of underdevelopment' to describe the evolution of the Third World countries. In his words, development and underdevelopment are two sides of one coin. In the world's economic system, satellite countries are grouped around, thus dependent on, metropolitan centres, and they become increasingly impoverished by this dependency because they have no control over the terms of trade. Wallerstein (1974) elaborated a more sophisticated world system theory which divided the capitalist world economy into the core, the semi-periphery, the periphery and the external arena, arguing that this system evolved from the 16th century along with processes of industrialisation and colonisation. Eventually, the core countries have firmly established a position in which they are able to exploit the resources of the peripheral countries for their own ends (Giddens 1993; Lauer 1991).

This Marxist perspective is concerned largely with the economic conflict between nations of different levels of development. While valid, it confines itself to analysing global cultural phenomenon. If, however, we treat the culture industry as also embodying representations of the capitalist world system and view it as an ideological apparatus whereby the core nations may expand and extract resources from dependent nations, we can use these theories of development as metaphors for the discussion of the development of global children's literature.

\section{Problems and Phenomena \\ in Taiwan's Children's Literature}

As a Taiwanese graduate student completes most of his/her coursework, and searches for a proper topic for a thesis, he/she will at once find that it is extremely difficult to choose one among a limited list. During the past decade since our institute (Graduate Institute of Children's Literature, National Taitung University, Taiwan) was established, students have explored a handful of well-known Taiwanese authors. Students have even undertaken theses on minor authors whose work is scarcely appropriate for postgraduate study, only to find that it is impossible, writing on the work of such authors, to reach the necessary length for a thesis. The reason is clear enough. Since the subject is an author study, intensive close reading becomes an essential component of the project, and the work of only a few authors can sustain a project of the length of a thesis, whether for reasons of quality or quantity. If students choose to deal with certain prominent writers who also publish a few children's books, they will find these works are so slight 
that they may give up and shift to another domain, e.g., foreign authors.

Students barely venture into historical studies, which remain uncultivated as an option for research because periods before 1945 seem to them remote, mainly because of the language barrier. To attempt a study of children's literature before 1945, students have to deal with the development of children's literature during the 50-year Japanese occupation (1895-1945), and most research at that period was published in Japanese (Duh \& Desmet 2004). It is a difficult matter to dissuade or discourage students from studying works of their native authors, or at least, those written in their own language, but this is what commonly happens. Students seem more familiar with the forms and pleasures which have been associated with children's literature defined as Western, and more and more translations in different genres become available in Taiwan.

Despite the appearance of prosperity in the marketplace, children's literature in Taiwan fails to demonstrate a balanced development. Children's books are predominantly Western imports, mostly translations from the work of English speaking authors. The cult of foreign authors has become so evident that Taiwanese authors are relegated to the periphery. Readers are impressed by the diversity of style and creativity demonstrated by foreign writers, and feel that Taiwanese works are inferior. They tend to ignore the fact that relatively few mainstream authors have been introduced to the marketplace, and become suspicious of anything by Taiwanese authors. In other words, the audience's taste has been shaped and constantly reinforced by the cultural products of the West. The aesthetic criteria of intellectuals, in this process, are also assimilated into the mainstream. It sounds paradoxical that while obviously underdevelopment is the norm in the production of children's literature in Taiwan (and probably in other countries as well), overdevelopment in production is also an alarming phenomenon. Publishers in Taiwan feel compelled to produce books in accordance with the emerging and changing tastes of the shrinking audience of young readers. They have to compete more fiercely with overseas producers in regard to the content of books, their variety and their price, yet sales of Taiwanese books drop drastically. Some publishers resort to direct importation in response to the ideology of globalisation, and most rely on translation. Both these strategies solve problems while creating others. The children's literature market in Taiwan is overwhelmingly Western, and so is academic work in the field. The cultural hegemony of the West is so manifest that it is liable to suffocate the growth of a national children's literature.

\section{The Meaning of Hegemony}

In discussing the concept of hegemony, Marxist theorists immediately come to mind. Sometimes the word 'hegemony' is associated with terms such as ideology, imperialism, domination, reproduction and legitimacy, but it is not my intention to deal with this issue in such a strongly political sense. Let me begin with a classic statement by Marx \& Engels:

The ideas of the ruling class are in every epoch the ruling ideas, i.e. the class which is the ruling material force of society, is at the same time its ruling intellectual force......it is self-evident that they do this in its whole range, hence among other things rule also as thinkers, as producers of ideas, and regulate the production and distribution of ideas of their age: thus their ideas are the ruling ideas of the epoch.

(Marx \& Engels 1947, p.39)

Here the ruling ideas that perpetuate intellectual power are seen as the function of hegemony. Althusser extended the thesis to propose that

...unlikesocialformations characterized by slavery
or serfdom, this reproduction of skills of labor
power tends decreasingly to be provided for 'on
the spot', but is achieved more and more outside
production: bythe capitalist education system, and
by other instances and institutions.

(Althusser 1971, p.132)

Althusser later called this mechanism of capitalist reproduction the Ideological State Apparatus (ISA).

The concept of hegemony is most frequently related to the writings of Gramsci, who indicated in his Selections from the Prison Notebooks, that 'the supremacy of a social group manifests itself in two ways, as "domination" and 
as "intellectual and moral leadership" (Gramsci 1971, p.376). The definition of hegemony is complicated by these disparate meanings. Anderson clarifies the concept by stating that,

...it is the cultural ascendancy of the ruling class that essentially ensures the stability of the capitalistic order. For in Gramsci's usage here, hegemony means the ideological subordination of the working class by the bourgeoisie, which enables it to rule by consent.

(Anderson 1976, p.26)

The concepts of hegemony and ideology intermingle with each other in a way that is potentially confusing. Williams distinguishes hegemony from ideology and indicates that 'it is seen to depend for its hold not only on its expression of interests of a ruling class but also on its acceptance as "normal reality" or "commonsense" by those in practice subordinated to it' (Williams 1988, p.145).

The sociological ideas I have outlined are centred in notions of state power and class structures within nation states. What are their implications for global power relations? As I indicated at the beginning, this paper adopts perspectives from the sociology of development, which conceives of the world as a hierarchical formation with the industrial capitalist countries at the top, exercising their power to extract interests from the subordinated lower echelons. Cultural hegemony at an international scale thus serves to legitimate and reproduce supremacy just as the Ideological State Apparatus functions in the state. To be sure, it is inadequate to apply this analogy without reservation. Although hegemony usually carries connotations of cultural imperialism, this is a somewhat mistaken view because the latter implies a conscious power manipulation for exploitation while the former is an unconscious logic of uneven power relations. Cultural hegemony may run so deep as to become an epistemological issue in literature, affecting its forms, contents, categories and so on, rather than a political issue.

\section{Western Categorisation of Children's Literature}

The most convenient way to explore how Western scholars define children's literature is to see how they categorise it, since categorising items defines what is possible to be known. Categorisation includes and excludes items. Eventually it becomes an habitual practice, enabling us to select, evaluate and classify works in the literary realm. A system of categorisation may be constructed historically, with certain ideological considerations, in response to pedagogical purposes and evolved through social and cultural changes (Bernstein 1971). Finally it evolves as educational knowledge. Though culturally determined as most knowledge can be, it is conceived as universal when the prevailing power defines it as true. In the categorising process of children's literature, factors such as the nature of childhood, the psychological development of children, the aesthetic value of literary form and certain social functions are all taken into consideration. Then what contents and genres are categorised in the body of texts known as children's literature?

If we select a few widely used textbooks published and republished in the past decade we can see how authors organise studies children's literature in a consistent way. Sutherland (1997) divides children's literature into Folktales, Fables, Myths, and Epics, Modern Fantasy, Poetry, Modern Fiction, Historical Fiction, Biography and Informational Books. Huck, Helper, Hickman \& Kiefer (1997) use roughly the same categories with the obvious addition of Picture Storybooks. In the 7th edition of her book, Luckens (2003) creates a more sophisticated category to include Realism, Formula Fiction, Fantasy, Traditional Tales, Rhyme to Poetry, Nonfiction (which consists of Biography and Informational Books). And Gangi (2004), the newest of this list, incorporates Picture Books, Poetry, Drama, Folklore from the Oral Tradition, Informational Books, Historical Fiction, Biography, Contemporary Realism, and Fantasy and Science Fiction. There are many subtypes under each major genre and the authors give different weight according to their priorities. Over the last three decades or so, the visual dimension of children's literature (in picture books, animations, film) has been increasingly emphasised. With their genres and sub-genres, these textbooks may seem to have exhausted all the possible forms of children's literature in all cultures at all times. 
Some notable critics seem to ignore genre boundaries and treat children's book more holistically. For instance, Stephens (1992) incorporates fantasy and picture books into his discussion of 'fiction'. Nodelman and Reimer warn about an over-emphasis on genre distinctions and suggest that:

... the main virtue on thinking about genre is not to provide readers with easy rules to follow in understanding or making judgments about texts. It is that it allows readers to perceive the variations and modifications and to think about their significance. Once more, seeing what texts have in common allows a focus on the far more interesting question of their differences.

(Nodelman and Reimer 2003, p. 187)

At the end of their book, they discuss poetry, picture books and fairy tales and myths as genres. Another notable example is Saxby's historical study of Australian children's literature. Unlike the genre categorisation of children's literature prevalent in North America, Saxby (1971) distinguishes five categories of children's stories, those of adventure, family stories, fantasy, bird and beast, and aborigines and race relations. This form of simple categorisation focuses on the major themes and forms which occur in most children's literature.

The fact that Stephens, Nodelman and Reimer and Saxby categorise children's texts in ways different from those common in textbooks from the United States demonstrates that genre categories are not universal, and that scholars can choose to categorise or not; or to adopt quite different genre categories. The reason that models of genre adopted by Taiwanese students and scholars are in line with American systems of categorisation is that these systems are dominant. Thus cultural hegemony defines and determines what is to be considered as a legitimate arena for the creation and study of children's literature. It becomes evident that while Taiwan is dependent on the US rather than on other Western countries in the economic sphere, such dependency has its counterpart in the cultural domain as literary knowledge. The production and consumption of children's books in Taiwan is then organised according to this seemingly 'objective' knowledge.

\section{The Influence of Categorisation}

Due to the cultural supremacy that has derived from the influx of Western cultural products of all kind, people in other countries become accustomed to evaluating aesthetic products according to Western criteria. Just as Hollywood stands for movies, so Disney and Dreamwork stand for cartoons, which diminishes the film industry of other countries. Similarly, children's literature in English as a cultural industry stands for the entire body of such texts, and this can exclude or marginalise literatures from 'other' countries. I do not claim that this occurs because of the intentions of those involved in this area of cultural production, but because of the cultural logic of capitalistic production.

The significance of categorisation in children's literature derives from the fact that it involves a dialectical knowledge/ power relation. People tend to adopt some form of Western taxonomy uncritically to define the boundaries of children's literature. At first glance, this seems unexceptionable, because notions of genre are so comprehensive that virtually any subtype of children's literature can be located somewhere. Again, the problem remains: 'Who defines?' Not only does the definition determine what to include, but also priorities or emphases. In the Chinese speaking world, research in children's literature is limited, unlike research into oral traditions of folklore, which have long been the domain of ethnologists and folklorists. Other kinds of text, like Chinese swordsman novels, which combines elements of fantasy, realism, historical fiction and Chinese philosophy, are not susceptible to categorisation and are therefore excluded. Once Western taxonomies are conceived as the most legitimate framework, writers or researchers may disregard the literary products of their own cultures in order to adjust to a pseudo-universal standard.

Some examples may suffice to highlight the situation. For instance, the category of high fantasy suggests Tolkien's Lord of the Rings trilogy, Lewis's Chronicles of Narnia series, and Le Guin's Earthsea books, but not Wu Chen An's Journey to the West, or Hsu Jong Ling's Creation of Gods. Perrault, the Grimms, Andersen, and Wilde have long been considered great figures in fairy tales, while $\mathrm{Pu}$ Sung Ling, the creator of Strange Tales from Liaozhai, 
which contains voluminous stories of fox fairies and mysteries, is ignored. An even more marginalised case is Can Bao's Anecdotes about Spirits and Immortals, which was compiled in about 400 A.D. and considered by some scholars as the prototype of Chinese 'fairy' tales. College students in Taiwan may be more familiar with Swift's Gulliver's Travel than Li Zu Jen's Flowers in the Mirror, though both share common elements such as satirical treatment of adventures to fantasy lands.

Chinese Swordsman novels, sometimes inappropriately compared to fairy tales, serve as an outstanding example for our discussion of categorisation. Chinese Swordsman novels, despite their massive audience, are still excluded or largely ignored from scholarship in children's literature due to their uniqueness (thus unclassifiable in terms of Western taxonomy). Most Western people learn about, thus misconceive, this literary genre through Kung Fu movies. The pleasure of reading Chinese Swordsman novels is very delightful and a wonderful experience commonly shared by young adults in Taiwan, males and females alike (though with certain gender variations). The characters in this genre are rich and varied, including intellectuals, beggars, monks, nuns, recluses, fortune-tellers, vagrant girls, chivalrous people wandering around, beautiful women with varied dispositions. These characters engage in battles for power using maps for hidden treasure, or martial arts scrolls, and are concerned with traditional values such as loyalty, filial piety, integrity and righteousness. Revenge and repayment are common themes. The characters look upon death indifferently, and the duel scene is the most common plot component. The climax of the story is usually a battle between two major forces. The tactics for elaborating the plot are extremely similar to high fantasy. Before becoming a hero who cares about the safety of the imagined world, the young protagonist must go through various kinds of tribulations and tests, much like the main characters in stories of Bildungsroman. The outstanding Swordsman novel often reveals the erudition of its author. The divinations, the medical skill, the mastery in playing chess, the knowledge with medical herb and poisons are the miscellaneous tricks needed in order to survive in the swordsman's world. Exotic plants and rare animals add more pleasure and allow for imagination. The most exciting aspect of the genre is dialogue between opposing characters, which are quick-witted and full of tension. Some people treat Chinese Swordsman novel as fairytales for adults. This juxtaposition is not quite adequate because it implies that adult readers intentionally place themselves in a chimerical world of swordsmen, but neglects the fact that some outstanding novelists have deliberately framed the story in accordance with historical events to express their personal perspectives and judgments.

The core value of Chinese Swordsman novels lies in their embodiment and extension of Chinese classical literature and traditional culture. The application of ancient poesy nearly reaches its limit. Besides their lyrical effects, they also serve as the inspiration for kungfu gambits. Ideas deeply embedded in Chinese consciousness, such as Confucianism, Taoism heritage, Buddhism heart law, and Book of Changes (a.k.a. I-Ching) constantly appear in the dialogue of characters. Although Swordsman novels are mainly fantasy literature, they are not completely so. Many a writer has set out to provide a historical context for the story, giving readers the impression that they are reading an unofficial or legendary history which uncovers historical truth. In order to strengthen this effect, writers may add paintings of the Imperial Palace showing the spatial-temporal setting. This peritextual information includes royal ritual, the portraits of the imperial family, landscape painting, weapons, battle steed, or dresses of that time. Several successful authors are particularly skillful in providing this kind of historical backdrop, directing the reader's imagination along with the lines of factual historical thinking. In short, Swordsman novels consist of elements of both fantasy and the historical novel.

The Swordsman novel is a peculiar genre in the Chinesespeaking world, and its uniqueness is precisely what invests it with a special glamour. Anyone well-versed in Chinese culture possesses more or less knowledge of ancient poetry, which is characterised by lyrical language. Although Swordsman novels abound with episodes of fighting, they are rich with literary elements whose subtlety outweighs its more boisterous components. The swordsman novel universe encompasses the art of Chinese healing practices, which have been deeply influenced by Taoism and I-Ching; The Art of War; tea customs; and chess, calligraphy and 
painting, all components of traditional Chinese literature. Should it be classified according to Western taxonomies of children's literature, the swordsman novel universe certainly possesses a sufficiently vast framework to merit the label of high fantasy: chimerical animals roaming around mountains and lagoons, clashes between good and evil, a hero's near-death ordeals prior to his ultimate triumph. However, because the context of this form of high fantasy is utterly Chinese, it is necessary for the reader to be equipped with considerable knowledge of the culture to be able to appreciate it. The extent to which it can be adequately translated is limited.

Another excellent example of the limitations of categorisation is provided by $\mathrm{Pu}$ Songling's Strange Tales from Liaozhai, which was considered one of the greatest masterpieces ever produced in China. Pu has successfully created a personified character type collectively called 'fox fairy' which can be good or evil, male or female. Fox fairies are neither ghosts nor immortals with capacity to transform into humans. In most such stories, female fox fairies use their magic power to attract and help downtrodden young scholars or the oppressed to gain what they deserve and restore justice in an unexpected way. Regardless of its wide readership, Strange Tales is seldom considered children's literature. Most young readers cannot appreciate it in its original form but have to read a simplified, plain language version so that the pleasure of the story is largely dissipated. Linguistic problems are always inherent in classifying classical fictions as children's literature. They have to be rewritten to become readable for children. But once the classical language is translated into the vernacular, the literary quality is lost. Another problem is that 'fox fairies', though attractive, are not what children in Taiwan conceive as fairies that they encounter in Western fairy tales or cartoon. Such works are always shelved along with the simplified classical literature section of children's bookstores in Taiwan, not in the same fairy tales shelves along with Andersen, Calvino, the Grimms, MacDonald or Wilde. Categorisation by publishers has an invisible and lasting effect for children and their parents to define what children's literature contains. Eventually, many classical fictions with excellent qualities as children's literature may be forgotten in this categorising process.
It is quite perplexing that students seldom venture into their own fantasyland for inspiration. One of the reasons is because Chinese classics were not written in plain language. But if foreign languages can be translated and become popular, why can the literary Chinese language not be rendered more readable? Adaptations and brief versions of Chinese classics are still published with minimal success. Flowers in the Mirror, one of the best Chinese classical novels, became popular when it was compared with Harry Potter, although only for a very short period of time. The story relates to flower spirits, Immortals, grotesque creatures, and imaginative mountains with the author's account of a 'Tao cultivating' journey of its protagonist. The translator of this book, Lin Tai-yi said of it:

[Flowers in the Mirror] is essentially a social
commentary and a human satire. But it is also a
historical romance, a fairy tale, an allegory, and in
its originalform, an built-in anthologyof expertise
in the various fields of the author's interest, was
linked together by sheer outrageous invention.
Certainly it is one of the most original works in
Chinese literature, and there is nothing like it in
Western literature either unless we think of a work
which has the combined nature of Grimm's fairy
tales, Gulliver's travels, Aesop's Fables, and the
Odyssey, with Alice in Wonderland thrown in for
good measures. (Lin 1965, p. 6)

The examples of Chinese Swordsman novel, Strange Tales of Liaozhai and Flowers in the Mirror highlight the fact that categorisation is arbitrary. These works cannot be neatly classified into a particular literary category. Rather, they run across various genres in a work. They possess the merits of diversity. But unfortunately, by applying popular Western, or more precisely American, categorisation in children's literature, they may belong nowhere.

\section{An Alternative to Categorising}

Ironically, sometimes it is Westerners who appreciate Chinese classical texts and recognise them as children's literature. For instance, Roberts (1979) translated and edited Chinese Fairy Tales \& Fantasies, which collected stories dating from the fifth century B.C. to the eighteenth 
A.D. Roberts conceived the tales from two major Chinese philosophical traditions: Confucianism and Taoism. The former represented the dominant view of order and authority, while the later represented the subordinated. The collected tales speak for the lower order of society. He then categorised them to include tales of enchantment and magic, tales of folly and greed, the animal kingdom, ghosts and souls, judges and diplomats, and an unofficial history of Confucian academy. The way he classified tales does not accord with any preexisting model. Rather, he clustered the tales systematically so that the Chinese cultural flavor can be largely preserved without sacrificing order. The work carried out by Roberts implies that when categorisation is necessary, it is better carried out inductively, rather than by applying an abstract principle of categorisation which was evolved from the Western cultural context.

Be it a global phenomenon or not, younger generations of Taiwanese readers are becoming alienated from the tradition of their own classical literature. It seems that nowadays even translated Western works are less distant from their taste than are Chinese works, contemporary or ancient. Ideological rather than linguistic issues explain the absence of readership. As a result, as graduate students timidly approach their professors and express their ideas of, say, comparing Journey to the West with Lord of the Rings, or taking Chinese swordsman novels as a topic, they often add, 'Can it be counted as...?' The uneasiness and lack of confidence in this can be contributed to their reception of Western categorisation, which is so deeply rooted and unconsciously constructed that they have to question the 'legitimacy' of their intended task before they really launch on it.

The cultural industry in Taiwan, which is usually very responsive to the marketplace, plays a crucial role in the uneven development of different genres. Publishers favour picture books and modern fantasy (thanks to the Horry Potter hurricane) and largely ignore other genres. Sometimes they find a handful of promising writers and decide to publish their works, but only to supplement their production. Correspondingly, researchers lean to whatever texts become available for study. The interplay between academic research and cultural industry contributes to the dominance of Western books, as well as the declining trend of Taiwanese texts. The development of dependency is no less evident in the cultural than in the economic sphere.

\section{Some Considerations and Discussions}

Can 'other' people in different parts of the world disenchant themselves from the spell of Western categorisation? Can they free themselves from the cultural hegemony of the West? Or can they create a taxonomy that is more conducive to the development of children's literature as a whole? These questions are interconnected, and no easy answer can be addressed to the solution of the problems.

Paradoxically enough, my first suggestion is to learn from the Western experience of categorising children's literature. Categorisation is a dynamic and ever changing process. It has to incorporate new elements like media and digital technology into the framework and interact with global social changes. As we noted earlier, taxonomies are constantly modified to adjust priorities, incorporate new forms and omit the outdated. Unlimited listing is meaningless because it blurs the focus and creates more chaos. A genre may take decades and centuries to evolve. Given the diversity of Chinese traditions, the folklore collected by ethnologists could be cultivated as literary wealth. But it takes more Grimms, Calvino and Tolstoy to tell and retell and make it happen.

Liberation from the confinement of Western categorisation does not involve inventing a different one. Sometimes it may imply that an omission is necessary when literary forms change and adapt. If European fairy tales grow out of their geographical origins, people in other countries cannot and should not write fairy tales like Perrault or the Grimms. In other words, they have to define that term from their own cultural context. Maybe they should give up that word and replace it with another if they are to develop a culturally distinctive genre. As indicated above, an inductive method, which grounds categorisation from works, may be superior to a deductive one, which relies on ready-made taxonomies. For instance, if Taiwanese children are exposed to a stereotype of fairies from Disney cartoons, they may exclude others with different images. Or since Chinese classical fictions contains more diverse spiritual beings than other cultures, why not coin a more 
comprehensive term rather than fairy tales to include stories of Souls, Spirits, Immortals, Foxes, Fairies, Underworld gods and others? Sometimes a concept can be misled by translation. For example, fairy tales are literally translated as 'children's tales'. It contributes to a very narrow definition of that term and limits its readership. Renaming a translated term may be necessary to correspond to its cultural reality. .

Although picture books and fantasy have become more popular, it is formula romance, historical fiction, and Chinese swordsman novels that attract most young adults in Taiwan, female and male. Other genres of children's literature, though highly valued, are little read. For example, Newberry Medal award-winning novels are rarely known outside the circle of children's literature. This suggests that popular forms of children's literature deserve more attention. The binary opposition between children's literature and literature for adults, though evolved over time, is arbitrary. There must be many elements shared by both. Or as Nodelman and Reimer (2003) suggest, their differences are much less significant than the similarities. By so doing, writers should aspire to create sound children's literature as defined by their culture, not others. The profound tradition of Chinese classical literature can be a great resource for children's literature. Romance of Three Kingdoms, Outlaws of the Marsh, Dreams of Red Chamber, Journey to the West, Flowers in the Mirror, Creation of Gods, and Strange tales of Liaozhai are great novels, to name a few. We should not merely reprint them and claim what elements of children's literature are inherent in them or simply produce shorter, easier versions for the young. Rather, more talents like Mary and Charles Lamb are needed to rewrite and retell the classics specifically for children. To counter cultural hegemony implies to create a different one. Choosing to follow the prevailing norms is to perpetuate the status quo.

When the conventional categorisation is demythologised and a counter hegemony is well grounded, a new taxonomy of children's literature can emerge. Such a taxonomy may grow out of cultural context, literary tradition, economic condition, ecological factor and social transformation, not out of an ostentatious intention to be different. It may be short, simple and straightforward. It will grow and change. Just like the great framework of English children's literature, it may embark on the process of constant selfcategorising.

\section{Conclusion}

Reasons for the underdevelopment of children's literature in 'other' worlds vary. I do not support the passive and somewhat pessimistic perspective that cultural dependency will perpetuate and indicate the limitation of Marxist theory in explaining that phenomenon. I also avoid the reductionism that would suggest that cultural hegemony is merely a representation of dominant/dominated power relations. This is too simplistic and argument and may cause antagonism between East and West, core and peripheral. The analogy of development and its related metaphors are relevant in this global community. Investigating the issue by examining the concept of categorisation sheds a new light on the knowledge of literary construction. Furthermore, it implies that children's literature on both sides can flourish through a reciprocal categorisation process. Then, the 'struggle' between hegemonic powers may result in a harmonious collaboration for the enrichment of our literature.

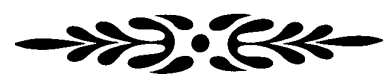

\section{REFERENCES}

Althusser, L. (1971) Lenin and Philosophy and Other Essays. New York, Monthly Review Press.

Anderson, P. (1976) 'The antinomies of Antonio Gramsci', in New Left Review, I/100:5-78.

Bernstein, B. (1971) 'On the classification and framing of educational knowledge', in M.F.D.Young (ed) Knowledge and Control, pp. 47-69. London, Collier-Macmillan.

Can, P. (2003) Anecdotes about Spirits and immortals. Peking, Foreign Language Press

Cardoso, F.H. (1972) 'Dependent capitalist development in Latin America', in New Left Review, I/74:83-95. 
Duh, M.C. (2006) 'The rise and fall of modern Chinese swordsman novel'. Paper presented to 7th International Conference of the Australasian Children's Literature Association for Research. July 12-14, 2006.

Duh, M.C. \& M. Desmet (2004) 'Children's literature in Taiwan', in P. Hunt (ed) International Companion Encyclopedia of Children's Literature. 2nd ed. London, Routledge.

Frank, A. (1969) Capitalism and Underdevelopment in Latin America. New York, Monthly Review press.

Gangi, J.M. (2004) Encountering Children's Literature: An Arts Approach. New York, Allyn and Bacon.

Giddens, A. (1993) Sociology. 2nd ed. Oxford, Polity Press.

Gramsci, A. (1990) 'Culture and ideological hegemony', in J.C. Alexander \& S. Seidman (eds) Culture and Society: contemporary debates, Cambridge, University Press, pp. 47-54.

Huck, C.S., Hepler, S., Hickman, J. \& Kiefer, B.Z. (1997) Children's Literature in the Elementary School. Chicago, Brown Benchmark.

Lauer, R. (1991) Perspectives on Social Change. 4th ed. Boston, Allyn and Bacon.

Li, J.C. (1965) Flowers in the Mirror. T.Y. Lin (trans). Berkeley, University of California Press.

Lukens, R.J. (2003) A Critical Handbook of Children's Literature. New York, Allyn and Bacon.

Marx, K. \& F. Engels (1947) The German ideology. New York, International Publishers.
Nodelman, P. \& M. Reimer (2003) The Pleasure of Children's Literature. 3rd ed. New York, Allyn and Bacon.

Pu, S. (1988) Strange Tales of Liaozhai. Y. Lu \& T. Chen \& L.Yang \& Z. Yang (trans). Hong Kong, Commercial.

Saxby, M. (1971) A History of Australian Children's Literature, 1941-1970. Sydney, Wentworth Books

Shi, N.A. (1986) Outlaws of the Marsh. K.C. Luo \& S. Sidney (trans). Hong Kong, Commercial.

Stephens, J. (1992) Language and Ideology in Children's Fiction. London, Longman.

Sutherland, Z. (1996) Children Books. New York, Longman.

Williams, R. (1988) 'Hegemony', in Keywords: a vocabulary of culture and society, pp. 144-6. London, Fontana.

Wu, C.N. (1977-1983) The Journey to the West. A.C. Yu (trans). Chicago, University Press.

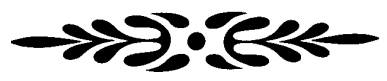

\section{BIOGRAPHICAL NOTE}

Ming Cherng Duh is associate professor and director of Graduate Institute of Children's Literature at National Taitung University, Taiwan. He holds a doctoral degree in sociology of education from University of Southern California. His research interests include sociology of literature, popular fiction and children's literature as well as history of childhood. He currently chairs a two-year project called 'Children's Literature and Process of Civilization'. 